\title{
Excipientes presentes em medicamentos antimicrobianos de diferentes marcas comerciais
}

\section{Excipients present in antimicrobial drugs of different trademarks}

\author{
Jaqueline Freitas do Nascimento 1 , Evanilza Aristides Santana ${ }^{2}$, Antonio Carlos Souza da \\ Silva Júnior 3 \\ ${ }^{1}$ Acadêmica de Farmácia, Instituto Macapaense do Melhor Ensino Superior. Macapá-AP Brasil. E-mail: jackllinefn@hotmail.com *Autor para \\ correspondência \\ ${ }^{2}$ Acadêmica de Farmácia, Instituto Macapaense do Melhor Ensino Superior. Macapá-AP Brasil. E-mail:evasantana@live.com \\ ${ }^{3}$ Pesquisador do Instituto de Pesquisas Científicas e Tecnológicas do Estado do Amapá-IEPA. Macapá-AP Brasil. E-mail: \\ jr_bio2005@yahoo.com.br
}

\section{Palavras-chave \\ Efeitos adversos \\ Saúde pública \\ Excipientes}

\begin{abstract}
O termo excipiente designa agentes que tem funções específicas e segurança avaliada que possibilitam a obtenção de formas farmacêuticas seguras, estáveis, atraentes e eficazes. Os excipientes possuem objetivos variados, tais como, auxiliar na preparação do medicamento, fornecer estabilidade, química, física e microbiológica ao produto, melhorar a biodisponibilidade do princípio ativo no organismo podendo influenciar na aceitabilidade do paciente além de manter a qualidade do produto durante a estocagem. $O$ trabalho teve como objetivo realizar um estudo do tipo retrospectivo e descritivo, com abordagem quantitativa través da contagem dos excipientes mais utilizados com uma abordagem farmacoepidemiológica transversal de bulas de antimicrobianos de diferentes marcas comerciais, destacando os possíveis efeitos adversos causados. No período de setembro a outubro de 2018 foram analisadas as bulas de 15 medicamentos antimicrobianos selecionados de forma aleatória de diferentes marcas comerciais disponíveis no mercado brasileiro, nas formas sólidas, liquidas e semissólidas. Das 15 formulações farmacêuticas analisadas, seis eram comprimidos (40\%), três eram cápsulas $(20 \%)$ duas eram soluções $(13,33 \%)$, duas eram pós $(13,33 \%)$, uma era pomada $(6,67 \%)$ e uma era creme $(6,67 \%)$. Todas as bulas detalhavam os excipientes presente das formulações. Foi possível constatar os excipientes metilparabeno, propilparabeno, manitol, povidona e álcool propilenoglicol, havendo a possibilidade de causar efeitos adversos. Com isso é necessário que ocorra o uso racional de medicamentos evitando a exposição de grupos suscetíveis a excipientes com potenciais de causar efeitos adversos. Apesar da obrigatoriedade das indústrias farmacêuticas a descrever a composição do excipientes na bula dos medicamentos.
\end{abstract}

The term excipient refers to agents having specific functions and assessed safety which enable the production of safe, stable, attractive and effective dosage forms. The excipients have varied objectives, such as assisting in the preparation of the medicament, providing stability, chemical, physical and microbiological to the product, improving the bioavailability of the active principle in the body and may influence the acceptability of the patient in addition to maintaining the quality of the product during storage. The aim of this study was to conduct a descriptive study by analyzing the antimicrobial package inserts of different commercial brands, quantifying which excipients are most used, and highlighting the possible adverse effects caused. From September to October 2018 the package inserts of 15 antimicrobial drugs selected from different commercial brands available in the Brazilian market were analyzed in the suspension, tablet, capsule and ointment presentations. Of the 15 pharmaceutical formulations analyzed, six were tablets (40\%), three were capsules (20\%) two were solutions (13.33\%), two were powders (13.33\%), one was ointment and one was cream (6.67\%). All package inserts detailed the excipients present in the formulations. The excipients were methylparaben, propylparaben, monitol, povidone and propylene glycol, with the possibility of causing adverse effects. This requires the rational use of drugs, avoiding the exposure of groups susceptible to excipients with the potential to cause adverse effects. Despite the obligation of pharmaceutical companies to describe the composition of the excipients in the package leaflet.

\section{INTRODUÇÃO}

O termo excipiente designa agentes que tem funções específicas e segurança avaliada que possibilitam a obtenção de formas farmacêuticas seguras, estáveis, atraentes e eficazes (VILLANOVA; SÁ, 2009). Os excipientes possuem objetivos variados, tais como, auxiliar na preparação do medicamento, fornecer estabilidade, química, física e microbiológica ao produto, melhorar a biodisponibilidade do princípio ativo no organismo podendo influenciar na aceitabilidade do paciente além de manter a qualidade do produto durante a estocagem (FERREIRA; VILLANOVA, 2012). 
Villanova e Sá (2009) ainda destacam que este tradicional conceito de excipiente vem passando por grande evolução. Sabe-se que o comportamento da forma farmacêutica depende de diversas variáveis no processo produtivo, da interação entre os excipientes e do impacto que estes podem apresentar sobre o princípio ativo, como foi visto anteriormente os excipientes são simples substâncias facilitadoras da administração e estabilizadoras das formas farmacêuticas, passaram a ser considerados, constituintes essenciais que garantem o desempenho do medicamento e segurança na obtenção do efeito terapêutico.

Para Balbani, Stelzer e Montovani (2006), os excipientes dos medicamentos de uso interno são classificados em: diluentes, desintegrantes, aglutinantes, lubrificantes, conservantes, aromatizantes, corantes, adoçantes, emulsificantes, solventes, espessantes, estabilizantes, antioxidantes, tensoativo. Esses compostos são responsáveis por manter os medicamentos estáveis, livres de microrganismos e adequados ao consumo por longo período de tempo, além de torná-los palatáveis, favorecendo a adesão ao tratamento pelo paciente. Aponta-se para a existência aproximadamente 1300 excipientes usados pela Indústria Farmacêutica (MONTEIRO, 2013).

A estabilidade dos produtos farmacêuticos depende muito de fatores ambientais como umidade, luz e temperatura além de outros fatores como as propriedades físicas e químicas das substâncias ativas presentes nos excipientes farmacêuticos, sua composição, processo de fabricação, tipo e propriedade dos materiais usados para embalagem (SOUZA; ALÉSSIO; GOMES, 2009).

Por muito tempo os excipientes foram descritos como substâncias inertes que não apresentavam ação farmacológica ou efeito toxicológico e, dessa maneira, nunca eram levados em consideração quando um paciente apresentava reações adversas. No entanto, sabe-se que estes compostos podem afetar diretamente o perfil de segurança dos medicamentos, podendo ser responsáveis por inúmeros efeitos adversos (SCADDING, 2009).

Dessa forma, o trabalho teve como objetivo realizar um estudo descritivo através de análise de bulas de antimicrobianos de diferentes marcas comerciais, quantificando quais excipientes são mais utilizados, e destacando os possíveis efeitos adversos causados.

\section{MÉTODOS}

Trata-se de um estudo do tipo retrospectivo e descritivo, com abordagem quantitativa realizado no período de setembro a outubro de 2018. Foram analisadas as bulas de 15 medicamentos antimicrobianos selecionados de forma aleatória de diferentes marcas comerciais disponíveis no mercado brasileiro, nas formas sólidas, liquidas e semisólidas. Anotou-se os dados referentes a presença de excipientes, destacando suas funções de acordo com o Handbook of pharmaceutical excipientes (ROWE; SHESKEY; OWEN, 2006) tais como: conservantes, diluentes, aglutinantes, desintegrantes, lubrificantes, aromatizantes, dessecantes, adsorventes, viscosificante, solubilizantes, corantes, adoçantes, plastificantes, molhantes, anticoagulantes, acidificantes, emulsificantes, solventes, espessantes, estabilizantes, antioxidantes, emolientes. A frequência relativa foi a medida tomada dos excipientes para verificar os mais encontrados e a descrição de seus possíveis efeitos adversos foi feita de acordo com o relatado na literatura.

A revisão de literatura foi do tipo narrativa, sem critérios explícitos e sistemáticos de busca, seguida de uma análise crítica. Sendo realizada a partir de um mapeamento de material científico, dentre eles artigos, resumos, livros, teses e dissertações disponíveis na internet, da qual a temática abordasse efeitos adversos relacionados aos excipientes.

\section{RESULTADOS E DISCUSSÃO}

Das 15 formulações farmacêuticas analisadas presentes na tabela 1 , seis eram comprimidos $(40 \%)$, três eram cápsulas (20\%) duas eram soluções $(13,33 \%)$, duas eram pós $(13,33 \%)$, uma era pomada $(6,67 \%)$ e uma era creme $(6,67 \%)$. Todas as bulas detalhavam os excipientes presente das formulações.

\section{Conservantes}

Os conservantes tem como função prevenir o crescimento microbiano. Em relação ás informações apresentadas nas bulas, foram encontrados três componentes que tem como função serem conservantes: o Álcool etílico presente em dois medicamentos (Cefalexina e Cloridrato de Neomicina) e Metilparabeno e Propilparabeno presente no Cloridrato de Neomicina como apresentados na tabela 2.

Os Parabenos são ésteres do ácido p-hidroxibenzoico que possuem características como boa solubilidade em água, amplo espectro de atividade, além de serem incolores, inodoros e insípidos (AULTON, 2003; SONI et al., 2005). Os parabenos possuem variadas características que tem se tornado evidente quanto ao uso em conjunto, tem maior atividade em faixa de $\mathrm{pH} 4,5-7,5$, quando colocados em água possuem elevada estabilidade, tem largo espectro de atividade antimicrobiana e são eficazes contra bactérias e 
Tabela 1. Medicamentos analisados, princípios ativos e excipientes por fórmula farmacêutica.

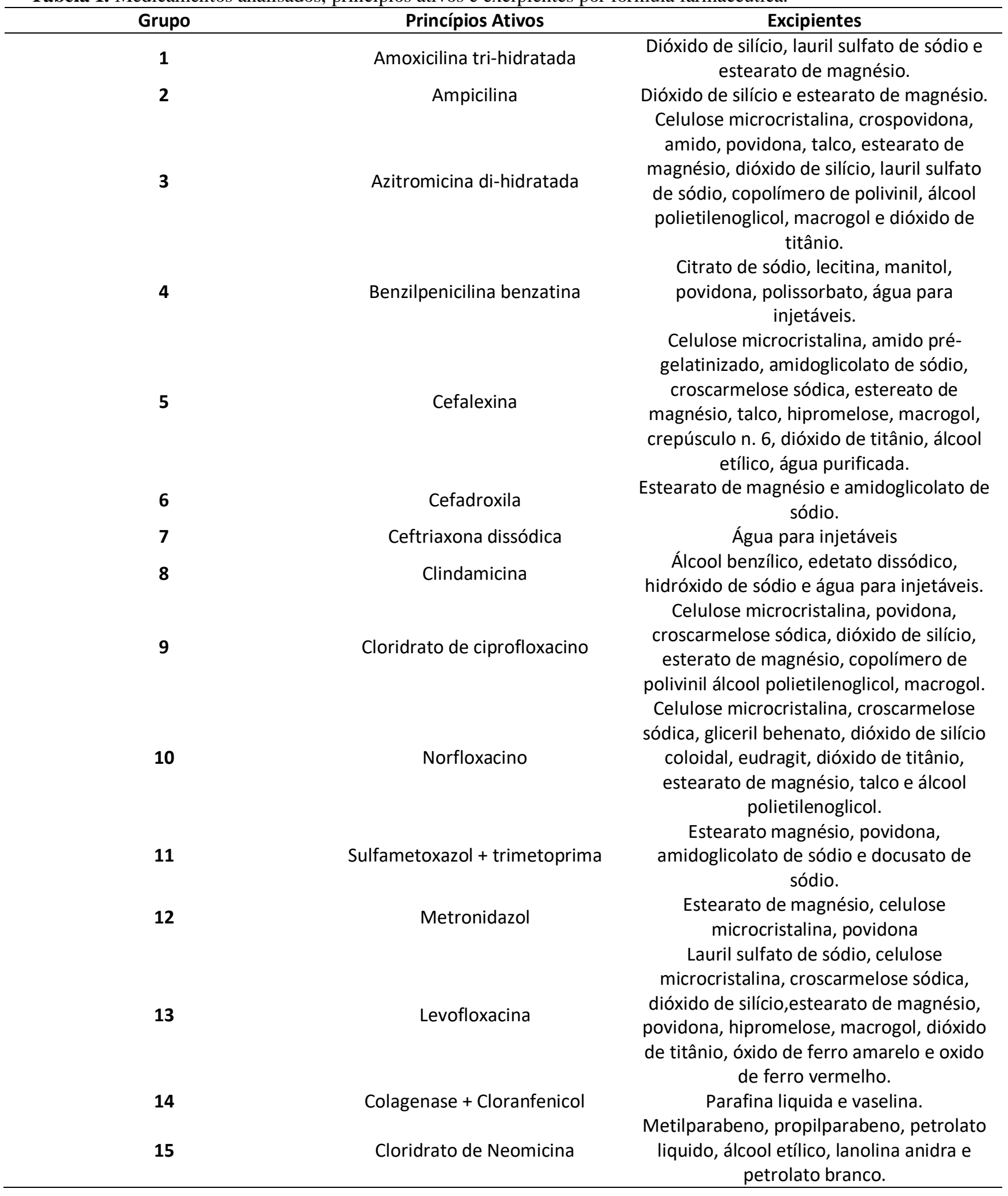

fungos (ELDER, 1984; SONI et al., 2005).

O mecanismo de ação dos parabenos é bastante complexa, porém ainda desconhecida. Sugere-se que os parabenos possuem ação sobre a síntese de DNA e RNA (FERNANDES et al., 2013). Sobre o mecanismo de transporte pelas membranas (FREESE; SHEU; GALLIERS, 1973), ou sobre enzimas-chave como fosforotransferases e ATPases (MA;

\section{MARQUIS, 1996)}

Vários casos de reações adversas a parabenos foram relatados por Soni et al. (2005), com destaque para as reações de hipersensibilidade, Parte dessas moléculas são convertidas ao ácido p-hidroxibenzóico durante seu metabolismo, sendo estruturalmente relacionado ao ácido acetilsalicílico (SILVA et al., 2008). 
Tabela 2. Frequência dos excipientes nas bulas avaliadas e suas respectivas funções nas formulações

\begin{tabular}{|c|c|c|}
\hline Excipiente & Função* & Frequência (\%) \\
\hline Dióxido de silício coloidal & $\begin{array}{l}\text { Adsorvente, agente anti-aglomerante, estabilizador de } \\
\text { emulsão, deslizante, agente de suspensão, } \\
\text { desintegrante de comprimidos, estabilizador térmico, } \\
\text { agente de aumento de viscosidade. }\end{array}$ & $1(40 \%)$ \\
\hline Estearato de magnésio & Lubrificante para comprimidos e cápsulas & $10(66,66 \%)$ \\
\hline Celulose microcristalina & $\begin{array}{l}\text { Agente de suspensão, adsorvente, diluentes para } \\
\text { comprimidos e cápsulas e desintegrante de comprimido }\end{array}$ & $6(40 \%)$ \\
\hline Amido & $\begin{array}{c}\text { Deslizante, diluente para comprimidos e cápsulas, } \\
\text { desintegrante. }\end{array}$ & $1(6,6 \%)$ \\
\hline Povidona & $\begin{array}{c}\text { Desintegrante, ajuda na dissolução e agente de } \\
\text { suspensão. }\end{array}$ & $6(40 \%)$ \\
\hline Talco & $\begin{array}{l}\text { Agente anti-aglomerante, deslizante, diluente para } \\
\text { comprimidos e cápsulas e lubrificante }\end{array}$ & $3(20 \%)$ \\
\hline Lauril sulfato de sódio & $\begin{array}{l}\text { Sulfactante, aniônico, detergente, agente emulsificante, } \\
\text { lubrificante, agente molhante e penetrante de pele. }\end{array}$ & $3(20 \%)$ \\
\hline Crospovidona & Desintegrante de comprimidos & $1(6,66 \%)$ \\
\hline Copolímero de polivinil & Agentes de revestimento & $2(13,33 \%)$ \\
\hline Álcool polietilenoglicol & $\begin{array}{c}\text { Base de pomada, plastificante, solvente, base de } \\
\text { supositório e lubrificantes de cápsulas e comprimidos. }\end{array}$ & $3(20 \%)$ \\
\hline Macrogol & $\begin{array}{l}\text { Potencializador de dissolução, tensoativo na iônico e } \\
\text { agente solubilizante. }\end{array}$ & $4(26,66 \%)$ \\
\hline Dióxido de titânio & Agente de revestimento ou pacificador e pigmento. & $4(26,66 \%)$ \\
\hline Citrato de sódio & $\begin{array}{c}\text { Agente alcalinizante, agente tamponante, emulsificante } \\
\text { e agente sequestrante. }\end{array}$ & $1(6,66 \%)$ \\
\hline Lecitina & $\begin{array}{l}\text { Agente emulsificante, agente solubilizante e emoliente. } \\
\text { Diluente para preparações liofilizadas, para }\end{array}$ & $1(6,66 \%)$ \\
\hline Manitol & $\begin{array}{l}\text { comprimidos e cápsulas, agente edulcorante e agente } \\
\text { de tonicidade. }\end{array}$ & $1(6,66 \%)$ \\
\hline Polissorbato & Molhante & $1(6,66 \%)$ \\
\hline Amidoglicolato de sódio & Desintegrante de comprimidos e cápsulas & $3(20 \%)$ \\
\hline Água para injetáveis & Solvente & $2(13,33 \%)$ \\
\hline Álcool benzílico & Solvente, desinfetante, & $1(6,66 \%)$ \\
\hline Edetato dissódico & Agente quelante & $1(6,66 \%)$ \\
\hline Hidróxido de sódio & Agente aucalinizante e agente de tamponamento & $1(6,66 \%)$ \\
\hline Croscarmelose sódica & Desintegrante de comprimidos e cápsulas & $4(26,66 \%)$ \\
\hline Crepúsculo n. 6 & Corante & $1(6,66 \%)$ \\
\hline Amido pré-gelatinizado & $\begin{array}{l}\text { Diluente de comprimidos e cápsulas, desintegrantes e } \\
\text { aglutinante. }\end{array}$ & $1(6,66 \%)$ \\
\hline Hipromelose & $\begin{array}{l}\text { Agente de revestimento, polímero controlador, agente } \\
\text { estabilizante, agente de suspensão, aglutinante, agente } \\
\text { de aumento de viscosidade }\end{array}$ & $2(13,33 \%)$ \\
\hline Álcool etílico & $\begin{array}{l}\text { Conservante antimicrobiano, desinfetante, penetrante } \\
\text { da pele, solvente. }\end{array}$ & $2(13,66 \%)$ \\
\hline Docusato de sódio & Sulfactante aniônico, agente molhante & $1(6,66 \%)$ \\
\hline Eudragit & Agente de revestimento & $1(6,66 \%)$ \\
\hline Parafina liquida & Base de pomada, agente endurecedor. & $1(6,66 \%)$ \\
\hline Vaselina & Umectantes & $1(6,66 \%)$ \\
\hline Metilparabeno & Conservante antimicrobiano & $1(6,66 \%)$ \\
\hline Propilparabeno & Conservante antimicrobiano & $1(6,66 \%)$ \\
\hline gliceril behenato & Agente de revestimento, aglutinante, lubrificante. & $1(6,66 \%)$ \\
\hline petrolato liquido & Emoliente, base de pomada. & $1(6,66 \%)$ \\
\hline petrolato branco & Emoliente, bases de pomada e plastificante. & $1(6,66 \%)$ \\
\hline lanolina anidra & Agente emulsificante e base de pomada & $1(6,66 \%)$ \\
\hline Água purificada & Solvente & $1(6,66 \%)$ \\
\hline Óxido de ferro amarelo & Corante & $1(6,66 \%)$ \\
\hline Óxido de ferro vermelho & Corante & $1(6,66 \%)$ \\
\hline
\end{tabular}

*Fonte: Rowe, Sheskey e Owen (2006). 


\section{Edulcorante}

Nas bulas avaliadas, foi constatado a presença de apenas um edulcorante, o manitol, que estava presente na Benzilpenicilina benzatina. Edulcorantes são substâncias usadas para correção do gosto de uma determinada preparação, tendo como exemplo variados açucares mais ou menos energéticos (RAMOS; MORAIS, 2013). Prisma et al. (2003) citam uma corrente de oposição ao excesso de edulcorantes nos comprimidos, pois isso daria a origem a intoxicação em crianças através de acidentes ocasionados pela ingestão dos medicamentos como guloseimas.

É importante destacar que o manitol, quando excipiente, apresenta baixos teores na formulação, porém, quando administrado em maiores concentrações, por via intravenosa pode causar reações de hipersensibilidade e por via oral pode gerar diarreia osmótica, e impacto na taxa de esvaziamento gástrico (URSINO et al., 2011). O manitol é um alditol que possui 6 carbonos, cuja fórmula química é C6H1406 e com ponto de fusão de 166 oC (MORANDINI, 2013).

\section{Corantes}

Os corantes encontrados nas formulações foram o dióxido de titânio (presente nos medicamentos Azitromicina di-hidratada; Cefalexina; Norfloxacino e Levofloxacina), crepúsculo n. 6 (Cefalexina), óxido de ferro amarelo e vermelho (presente na Levofloxacina). Estes são aditivos que tem como definição substância que confere, aumenta ou restaura a cor (FOOD INGREDIENTS BRASIL, 2016). Os corantes são misturados ao medicamento com a finalidade de produzir uma aparência diferente, para distinguir uma formulação característica de outras com aparência semelhante tornando os comprimidos mais atrativos (ABRANTES 2015).

Segundo Castro, Ahlert e Colet (2010), não foram relatados efeitos adversos com o uso de corantes em medicamento, mesmo assim, ainda é necessário informar no rótulo de antimicrobianos, além dos corantes utilizados na formulação, o seu teor empregado, permitindo, dessa forma verificar o cumprimento dos limites máximos preconizados na literatura.

Por outro lado, a Agência Internacional de Pesquisa sobre Câncer (IARC, International Agency for Research on Cancer), caracterizou em 2006 o dióxido de titânio (TiO2) como uma substancia com potencial cancerígeno a humanos (IARC, 2006). As pesquisas realizadas tiveram como resultados a indução de câncer no trato respiratório dos ratos após terem sido expostos ao TiO2. Enquanto que estudos realizados por Huang et al. (2009) e Trouiller et al. (2009) discorrem que nanopartículas de $\mathrm{TiO} 2$ levam a genotoxicidade e citotoxicidade em várias linhagens de cultura de células, bem como o seu alto potencial carcinogênico em modelos animais (HUANG et al, 2009; TROUILLER, 2009).

O dióxido de titânio no Brasil, é padronizado como um agente corante artificial (pigmento) pela Ministério da Saúde (BRASIL, 1977), porém não há uma declaração quanto aos valores máximos permitidos para uso, em qualquer matriz. A Food and Drugs Administration (FDA), que é um órgão governamental dos Estados Unidos, determina teores máximos de $1 \%(\mathrm{~m} / \mathrm{m})$ para dióxido de titânio, somente quando usado como corante alimentício (FDA, 2017).

\section{Lubrificante}

Os lubrificantes também merecem destaque, estes que são usados no processo de fabricação de comprimidos e cápsulas, com o intuito de minimizar o atrito entre o pó e as superfícies metálicas dos equipamentos. O lubrificante mais utilizado é o estearato de magnésio, encontrado neste trabalho em oito dos medicamentos avaliados (Amoxicilina tri-hidratada; Ampicilina; Azitromicina di-hidratada; Cefadroxila; Norfloxacino; sulfametoxazol + trimetoprima; Metronidazol e Levofloxacina), o seu efeito hidrofóbico, geralmente retarda a penetração de líquidos nos componentes presentes na formulação, diminuindo a velocidade de dissolução. Com isso, os efeitos podem ser minimizados através da adição concomitante de um diluente hidrofílico ou de um tensoativo solúvel em água (AULTON, 2005).

O estereato de magnésio, cuja formula química é C36H70MgO4 é um pó branco, impalpável, incompatível com ácidos, álcalis e sais de ferro. Com seu potencial hidrofóbico, ele é capaz de retardar a dissolução de formas farmacêuticas sólidas, precisando ser usado na menor concentração possível. A sua eficácia de lubrificação pode ser afetada pelas suas características físicas, sendo que o tempo para a mistura do estearato de magnésio deve ser controlado (FERRAZ, 2019).

\section{Diluente}

O diluente é o excipiente mais usado em formulações de sólidos orais com o intuito de aumentar a densidade bruta de um produto, ele precisa ser quimicamente inerte, ter propriedades farmacêuticas boa, não ser higroscópico e ter gosto aceitável (DA SILVA, 2013). Destas características, nem todas são encontradas em uma única substância, com isso variados produtos estão sendo utilizados como diluentes (AULTON, 2005). Das bulas avaliadas neste estudo foram encontrados três diluentes nos medicamentos, tais como, o 
Amido (Azitromicina di-hidratada); a celulose microcristalina (Azitromicina di-hidratada; Cefalexina; Cloridrato de ciprofloxacino; Norfloxacino; Metronidazol; Levofloxacina) e o talco (Azitromicina di-hidratada; Cefalexina e Norfloxacino).

O amido, com a fórmula química (C6H10O5)n, é um pó branco, fino, que possui variação nas suas características de formato e tamanho das partículas de acordo com sua origem botânica: amido de milho, batata, arroz e trigo, entre outros. É necessário uma atenção especial devido a contaminação por microrganismos. Ele possui baixas propriedades de fluxo, sendo, também, bastante higroscópico e pode conter até $15 \%$ de umidade. O amido é relativamente estável, não tendo relatos de incompatibilidade com componentes normalmente utilizados em fórmulas farmacêuticas sólidas (FERRAZ, 2019).

\section{Aglutinante}

Para melhorar a dissolução de fármacos que são pouco solúveis por causa das propriedades hidrofílicas das superfícies dos grânulos é feita a adição de aglutinantes (ABDOU; HANNA; MUHAMMAD, 2000). O uso de aglutinantes pode também favorecer a dissolução através da hidrofilização da superfície de contato entre as partículas do fármaco e os líquidos biológicos (DORNELAS et al., 2008). Contudo os aglutinantes encontrados nas bulas dos antimicrobianos foram o Amido pré-gelatinizado (Cefalexina); Hipromelose (Cefalexina e Levofloxacina) e o gliceril behenato (Norfloxacino)

\section{Desintegrante}

A presença na formulação de um agente desintegrante, tem como função facilitar a desagregação das cápsulas, fazendo com que a área superficial seja aumentada resultando na promoção da dissolução do fármaco (FERREIRA, 2010). Dos quinze medicamentos estudados a maioria apresentava algum desintegrante como a celulose microcristalina (Azitromicina di-hidratada; Cefalexina; Cloridrato de ciprofloxacino; Norfloxacino; Metronidazol; Levofloxacina) povidona (Azitromicina di-hidratada; Benzilpenicilina benzatina; Cloridrato de ciprofloxacino, sulfametoxazol+ trimetoprima, Metronidazol, Levofloxacina); croscarmelose sódica (Cefalexina; Cloridrato de ciprofloxacino; Norfloxacino; Levofloxacina).e amido glicolato de sódio (Cefalexina, Cefadroxila, sulfametoxazol + trimetoprima).

Destes, merece destaque a Povidona, onde já existem relatos de reações adversas em determinados medicamentos, foi constado por Monteiro (2013) que seu consumo por crianças pode causar Reações anafiláticas.

Molhante

Já os agentes molhantes são acrescentados na formulação com a finalidade de aumentar a molhabilidade do ativo. Sabe-se que para ser um pré-requisito para o processo de desintegração é preciso da molhabilidade da partícula (PURY et al, 2010). Os agentes molhantes encontrados neste trabalho foram Lauril sulfato de sódio (Amoxicilina tri-hidratada; Azitromicina di-hidratada e Levofloxacina), Polissorbato (Benzilpenicilina benzatina). No trabalho de Tije et al. (2003), foram relatados degeneração vesicular e reações de hipersensiibilidade aguda como efeitos adversos do polissorbato.

\section{Revestimento}

O revestimento é usado para mascarar odores e sabores desagradáveis, ter uma administração facilitada, entre outros, ele consiste em aplicar um material na superfície externa de uma partícula sólida (HOGAN, 2005). Foram encontrados neste trabalho os seguintes excipientes de revestimento, Copolímero de polivinil (Azitromicina dihidratada, Cloridrato de ciprofloxacino), Dióxido de titânio (Azitromicina di-hidratada, Cefalexina, Norfloxacino, Levofloxacina), Hipromelose (Cefalexina, Levofloxacina), Eudragit (Norfloxacino), gliceril behenato (Norfloxacino).

\section{Plastificante}

Já os plastificantes tem como objetivo melhorar as propriedades mecânicas do revestimento, facilitando a formação da película (FELTON; McGINITY, 1999). Resultando na diminuição da fragilidade e a incidência de rachaduras por gerar elasticidade e flexibilidade (ESERIAN; LOMBARDO, 2014). Os plastificantes encontrados nas formulações foram, o Álcool polietilenoglicol (Azitromicina di-hidratada, Cloridrato de ciprofloxacino, Norfloxacino) e o petrolato branco (Cloridrato de Neomicina). Destes, o Formulário terapêutico (BRASIL, 2008) menciona como efeitos adversos do Álcool polietilenoglicol a toxicidade em neotatos e a hipersenbibilidade para pacientes com queimaduras extensas.

\section{CONCLUSÕES}

Com a avaliação das informações presentes nas bulas dos antimicrobianos analisados, foi possível constatar a presença de excipientes com potenciais de causar efeitos adversos. Para mitigar tais problemas decorrentes desse consumo, é 
necessário que ocorra o uso racional de medicamentos evitando a exposição de grupos suscetíveis a tais excipientes. Ainda é importante ressaltar que apesar da obrigatoriedade das indústrias farmacêuticas a descrever a composição do excipientes na bula dos medicamentos (BRASIL, 2009), ainda é necessária uma legislação para fazer rotulagens mais apropriada com alertas nas bulas sobre as reações adversas provenientes dos excipientes.

Mesmo os excipientes sendo utilizados em concentrações muito reduzidas, ainda são capazes de desencadear reações adversas como foram citadas durante o trabalho. Outro fato importante, é a falta de leitura da bula por pacientes e profissionais da saúde ou mesmo pela falta de conhecimento a respeito de excipientes antes da prescrição de medicamentos, tornando fundamental a atuação do profissional farmacêutico para ajudar na maior segurança dos pacientes.

\section{REFERÊNCIAS}

ABDOU, H.M.; HANNA, S.; MUHAMMAD, N. Dissolution. In: GENERO A.R., ed. Remington: The science and practice of pharmacy. 20.ed. Baltimore: Lippincott Williams \& Wilkins. p.654-666. 2000.

AUTON, M.E. Delineamento de formas farmacêuticas. Porto alegre: Artmed, 2a ed. p.261, 2005.

BALBANI, A.P.S; STELZER, L.B; MONTOVANI, J.C. Excipientes de medicamentos e as informações da bula. Revista Brasileira de Otorrinolaringologia. São Paulo, v. 72, no 6, 2006.

BRASIL. Agencia nacional de vigilância sanitária. Resolução n 47, de 8 de setembro de 2009. Estabelece regras para elaboração, harmonização, atualização, publicação e disponibilização de bulas de medicamentos para pacientes e para profissionais de saúde. Diário oficial da união. Brasilia, DF,2009.

BRASIL. Comissão Nacional de Normas e Padrões para Alimentos, do Ministério da Saúde. Resolução no 44, de 1977. Considera corante a substância ou a mistura de substâncias que possuem a propriedade de conferir ou intensificar a coloração de alimento (e bebida). Diário Oficial da União. Poder Executivo, de 01 de fevereiro de $1978 . \quad$ Disponível em: http://portal.anvisa.gov.br/documents/33916/391619/RE SOLUCAO_CNNPA_44_1977.pdf/b8d43a0d-5c1b-4be1ba69-67f69cf55446. Acessado em: 17 jan 2019.

BRASIL. Ministério da Saúde. Secretaria de Ciência, Tecnologia e Insumos Estratégicos. Departamento de Assistência Farmacêutica e Insumos Estratégicos. Formulário terapêutico nacional 2008. - Brasília:
Ministério da Saúde, 2008. Disponível em: http://bvsms.saude.gov.br/bvs/publicacoes/formulario_t erapeutico_nacional_2008.pdf. Acessado em: 21 out 2018.

CASTRO, A.L.M; AHLERT, E.R; COLET, C.F. Avaliação do risco de reações adversas causadas por excipientes em formulações de anticoncepcionais. Revista contexto e saúde. v.10, n. 19, p. 146-149, 2010.

DA SILVA, D.C. Ensaios físicos dos excipientes e avaliação das farmacopeias. 53 f. Trabalho de conclusão de curso (Especialização em Tecnologia Industriais Farmacêuticas) - Fundação Oswaldo cruz, Rio de Janeiro, 2013.

DORNELAS, C.B; RESENDE, D.K; TAVARES, M.I.B, CABRAL, A.S.G.L.M. Preparação e avaliação reacional de nanocompósitos de PVP K-30- montmorilonita (natural e organicamente modificada) por difração de raios $X$. Polímeros: Ciência e Tecnologia. v.18, n.2, p. 187-192, 2008.

ELDER, R.L. Final reporto $\mathrm{n}$ the safety assessment of methylparaben, propylparaben. Journal of the American college of toxicology, v.3, p.147-209, 1984.

ESERIAN, J.K; LOMBARDO, M. Comprimidos revestidos por película: tipos de não-conformidades e suas causas. Revista Eletrônica de Farmácia. v. 11, n.3, p.32-47, 2014.

FDA. Food \& Drug Administration. Summary of color additives for use in United States in foods, drugs, cosmetics, and medical devices. 2017. Disponível em: http//www.fda.gov/ForIndustry/ColorAdditives/ColorAdd itivesInventories. Acessado em: 17 jan 2019.

FELTON, L.A.; McGINITY, J.W. Adhesion of polymeric films to pharmaceutical solids. European Journal of Pharmaceutics and Biopharmaceutics. v.47, n.1, p.3-14, 1999.

FERRAZ, H.G. Formas farmacêuticas sólidas: comprimidos e comprimidos revestidos. FCF/USP. Disponível em: https://edisciplinas.usp.br/pluginfile.php/3500709/mod_ resource/content/0/Comprimidos\%20e\%20comprimidos \%20revestidos.pdf, Acessado em: 10 fev 2019.

FERREIRA, A.O. Guia prático da farmácia magistral. 4 ed., versão ampliada. São Paulo: pharmabooks editora, 2010.

FERREIRA, A.O.; VILLANOVA, J. Excipientes e adjuvantes. Revista Brasileira de Farmácia. v.93, n.2, p.136-145, 2012. FOODS INGREDIENTS BRASIL. Corantes. Revista fi. n. 39, p.24-46, 2016.

FREESE, E.; SHEU, C. W.; GALLIERS, E. Function of lipophilic acids as antimicrobial food additives. Nature. v.241, n.5388, p.321-325, 1973.

HOGAN, J. Revestimento de comprimidos e multiparticulados. In: AULTON, M.E. Delineamento de formas farmacêuticas, 2. ed., Artmed: Porto Alegre, 2005, $677 \mathrm{p}$. 
HUANG, S.; CHUEH, P.J.; LIN, Y.; SHIH, T.; CHUANG, S. Disturbed mitotic progression and genome segregation are involved in cell transformation mediated by nano$\mathrm{TiO} 2$ long-term exposure. Toxicology and applied pharmacology. v.241, n.2, p.182-194, 2009.

IARC Monographs on the Evaluation of Carcinogenic Risks to Humans; "Carbon black, titanium dioxide and nonasbestiform talc", IARC, Lyon (france), 93, 2006.

MA, Y.; MARQUIS, R. E. Irreversible paraben inhibition of glycolysis by Streptococcus mutans GS-5. Letters in Applied Microbiology. v.23, n.5, p.329-333, 1996.

MONTEIRO, A.S.C. Segurança dos excipientes utilizados nos medicamentos genéricos numa população pediátrica. 176 f. Dissertação (Mestrado em Ciências Farmacêuticas) Universidade da beira interior, 2013.

MORANDINI, L.M.B. Isolamento, determinação estrutural e atividade microbiológica de moléculas bioativas no fungo ectomicorrízico Scleroderma UFSMSc1 (Persoon) fries. Tese de doutorado programa de pós-graduação em química da Universidade Federal de Santa Maria. 2013.

FERNANDES, J.P.S.; SAVINO, G.; AMARANTE, A.C.G.; SOUSA, M.R.; SILVA, G.R.; CIANCIULLI, M.E.; CORRÊA, M.F.; FERRARINI, M. Estudo das relações entre estrutura e atividade de parabenos: uma aula prática. Química Nova. v.36, n.6, p.890-893, 2013.

PINTO, T. J. A.; KANEKO, T. M.; OHARA, M. T.; Controle Biológico de Qualidade de Produtos Farmacêuticos, Correlatos e Cosméticos, 2a ed., Atheneu: São Paulo, 2003.

PRISTA, L.V.N.; ALVES, A.C.; MORGADO, R.; LOBO, J.S. Tecnologia farmacêutica. 6. Ed.v.1. Lisboa: fundação calouste gulbenkian, 2003.

PURY, V; DANTULIRI, A.K; KUMAR, N; BANSAL, A.K. Wettability and surfasse chemestry of crystalline and amorfos forms of a poorly water soluble drug. Europan jornal of pharmaceutical scienses. v.40, p.84-93, 2010.

RAMOS, G; MORAIS, D.C.M. Revisão de literatura sobre excipientes em farmácia de manipulação. Foco. v.4, n.5, p.11-26, 2013.

ROWE, R.C; SHESKEY, P.J; OWEN, S.C. Handbook of pharmaceutical excipientes. 5a ed - american pharmacists association, $2006945 \mathrm{f}$.

SCADDING, G. Pediatric allergy medications: review of currently available formulations. Current Medical Research and Opinion. v.25, n.8, p. 2069-2079, 2009.

SILVA, A.V.A; FONSECA, G.C; ARRAIS, P.S.D; FRANCELINO, E.V. Presença de excipientes com potencial para indução de reações adversas em medicamentos comercializados no Brasil. Revista brasileira de ciências farmacêuticas. v.44 n.3, p.388-405, 2008.

SONI, M.G; BURDOCK, G.A; TAYLOR, S.L; GREENBERG, N.A.
Safety assesment of propyl paraben: a review of the published literature. Food and chemical toxicology. v.39, n.6, p.513-532, 2005.

SOUZA, K.J.; ALÉSSIO, P.V.; GOMES, A.J.P.S. Desenvolvimento de excipiente específico para cápsulas de nifedipina preparadas magistralmente: parte I. Revista Ciências Farmacêuticas Básica e Aplicada. v.30, n.3, p.257- 261, 2009.

TIJE, A.J.; VERWEIJ, J.; LOOS, W.J.; SPARREBOOM, A. Pharmacological effects of formulation vehicles: implications for cancer chemotherapy. Clinical Pharmacokinetics. v.42, n.7, p.665-685, 2003.

TROUILLER, B.; RELIENE, R.; WESTBROOK, A.; SOLAIMANI, P.;SCHIESTL, R.H. Titanium dioxide nanoparticles induce DNA damage and genetic instability in vivo in mice. Cancer Research. v.68, n.22, p.8784-8789, 2009.

URSINO, M.G; POLUZZI, E.; CARAMELLA, C.; DE PONTI, F. Excipients in medicinal products used in gastroenterology as a possible cause of side effects. Regulatory Toxicology and Pharmacology. v.60, n.1, p.93-105, 2011.

VILLANOVA, J.C.O.; SÁ, V.R. Formas sólidas. In: VILLANOVA, J.C.O.; SÁ, V.R. Excipientes. Guia prático para padronização. Formas Farmacêuticas orais sólidas e líquidas. 2. ed. São Paulo: Pharmabooks. 2009. cap. 2. p.6-18.

Submissão: 21/11/2018

Aprovado para publicação: 26/02/2019 